\title{
Designing a control system based on SOC estimation of BMS for PV-Solar system
}

\author{
Yonis M. Yonis Buswig ${ }^{1 *}$, Ohirul Qays ${ }^{1, *}$, Azuka Affam ${ }^{1}$, Hani Albalawi ${ }^{2}$, Al- \\ Khalid Othman ${ }^{1}$, Norhuzaimin Julai ${ }^{1}, \operatorname{Sim} \mathrm{Sy} \mathrm{Yi}^{3}$
}

${ }^{1}$ Faculty of Engineering,

Universiti Malaysia Sarawak, Kuching, Sarawak, MALAYSIA

${ }^{2}$ Faculty of Engineering,

University of Tabuk, King Faisal Rd, Tabuk, SAUDI ARABIA

${ }^{3}$ Faculty of Engineering Technology,

Universiti Tun Hussein Onn Malaysia, Parit Raja, Johor, MALAYSIA

*Corresponding Author

DOI: https://doi.org/10.30880/ijie.2020.12.06.017

Received 08 April 2020; Accepted 04 June 2020; Available online 02 July 2020

\begin{abstract}
One of the major challenges for battery energy stowage system is to design a supervisory controller which can yield high energy concentration, reduced self-discharge rate and prolong the battery lifetime. A regulatory PVBattery Management System (BMS) based State of Charge (SOC) estimation is presented in this paper that optimally addresses the issues. The proposed control algorithm estimates SOC by Backpropagation Neural Network (BPNN) scheme and utilizes the Maximum Power Point Tracking (MPPT) scheme of the solar panels to take decision for charging, discharging or islanding mode of the Lead-Acid battery bank. A case study (SOC estimation) is demonstrated as well to depict the efficiency (Error $0.082 \%$ ) of the proposed model using real time data. The numerical simulation structured through real-time information concedes that the projected control mechanism is robust and accomplishes several objectives of integrated PV-BMS for instance avoiding overcharging and deep discharging manner under different solar radiations.
\end{abstract}

Keywords: BMS, SOC estimation, BPNN, PV

\section{Introduction}

Developing countries need to make use of sufficient potential of PV power sources to cover the incremental demand of energy security. Though the PV-diesel microgrid system involving maximum supervising action as well as without having energy storage system can afford the continual power supply in the unelectrified rural area, it may not be circumstantially companionable because of the dependence on fossil-fuels and total dispatched energy cost[1][2]. Moreover, an individual PV system is an incomplete basis of electricity supplier due to the power instability produced by unpredictable solar irradiance and atmospheric temperature. Hence, MPPT is used commonly with PV solar systems to maximize power extraction from PV supply. Reference [3] presented an exhaustive literature review on on-line and off-line procedures for PV MPPT system. Reference [4] evaluated the application of Incremental Conductance, Perturb \& Observe (P\&O) MPPT procedure depending of European Efficiency Test EN 50530 that was specially contrived for 
dynamic occurrence of PV system. Reference [5] simulated a modified P\&O MPPT algorithm via MATLAB/SIMULINK software that confines an exploration interval for $10 \%$ region of the power curve.

On the other hand, only PV modules cannot meet the load demand during cloudy day or night time. Thus, a Battery Management System (BMS) is mandatory to combine with a standalone PV system headed for providing power uninterruptedly throughout the day and night time [6][7]. Generally, Lead-acid batteries contain flat terminal voltage with relation to SOC of battery bank as presented in Fig.1. Moreover, the batteries in PV system are normally operating in $40 \%$ to $80 \%$ SOC range [8]. The voltage deviation in this series is below $0.55 \mathrm{~V}$. This small voltage changes can barely be cast-off to efficiently persuade the proper charging and discharging processes. In the preceding, there have been various attempts to develop optimum and innovative power control approaches for the PV-Battery integrated system to maintain a unremitting power allocation in lieu of load demand.. Reference [9] studied on grid connected 28.8kW PVBattery integrated system in MATLAB/SIMULINK software by implementing P\&O MPPT technique. The system showed power deviation $(1.7 \mathrm{~kW})$ between model prediction and actual power because of clouds, dust, snow cover and aging effect. Reference [10] considered grid scheduled blackouts for optimal operation of PV-Battery hybrid system and calculated battery SOC to prolong the battery lifetime. Reference [11] constructed 2nd order Equivalent Circuit Model (ECM) of Lead Acid battery aimed at domestic systems and considered open circuit voltage vs SOC non-linear correlation intended for low C-rate applications. Reference [12] introduced a fuzzy model to estimate SOC for Lead-Acid battery on behalf of Extended Kalman Filter (EKF) scheme.

However, there is no work done on proper control strategic for a standalone PV-Battery integrated system by monitoring the storage charge status till now. For this reason, the aim of this research is to illustrate an appropriate BMS for PV-Battery hybrid system based on battery SOC estimation technique including 2nd order Lead-Acid battery ECM. The remaining parts of the current paper is structured accordingly: Section 2 describes proposed methodology where Photovoltaic-Solar ECM and the MPPT enactment is explained in subsection A and B respectively. Subsection C and D is validated on battery ECM and BackPropagation Neural Network (BPNN) based SOC estimation technique correspondingly. The applicable simulated model along with a transitory dissertation for the anticipated system remains into section 3. Lastly, section 4 concludes the illustration of the paper.

\section{Methodology}

\subsection{PV Solar}

A corresponding circuit model of single diode PV cell is portrayed into Fig-2. It consists of several parameters such as a current source $I s c$, a series resistance $R s$, a shunt resistance $R s h$, diode current $I_{D}$, reverse saturation current $I_{0}$ shunt resistance current $I s h$, terminal/load voltage $V$ and PV cell power $P$ [13][14]. The circuit is not restricted only for a PV cell structure, any composite multicell system for instance a PV module, string, or array can be operated under uniform conditions. The current-voltage equation of the model is depicted from (1) to (3)

$$
\begin{gathered}
I_{D}=I_{0}\left(e^{\frac{q V}{K T}}-1\right) \\
V_{O C}=\frac{K T}{q} \ln \left(\frac{I_{S C}}{I_{0}}+1\right) \\
P=V * I=V I_{S C}-V I_{0}\left(e^{\frac{q V}{K T}}-1\right) \\
I=I_{S C}-I_{0}\left(e^{\frac{q V\left(1+R_{S}\right)}{K T}}-1\right)-\left(\frac{V(1+R s)}{R p}\right)
\end{gathered}
$$

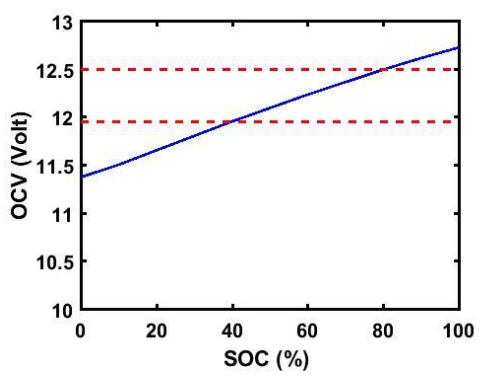

Fig. 1 - OCV vs SOC relationship for 12V Lead-Acid battery 


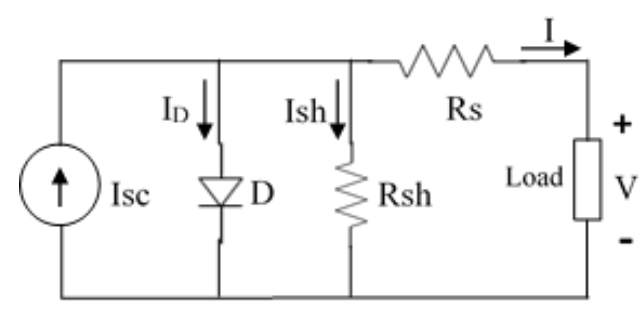

Fig. 2 - Single diode PV cell modeling

Where $q, K$ and $T$ are the electron charge $\left(1.60217657 \times 10^{-19}\right)$, Boltzmann constant $\left(1.3806488 \times 10^{-23}\right)$ and module temperature respectively. A more truthful equation for V-I characteristics of solar cell is clarified in equation (4) as a result of internal series and parallel resistance losses.

\subsection{MPPT}

P\&O is a widely MPPT technique owing to its simplicity of application and individuality of PV array parameters. This is an incessant procedure of scrutiny and agitation until the working point meets to the peak point [3][15]. The algorithm relates time (P) of the PV power and voltages by the sample period (P-1) and foresees time of MPPT. When power adjustment is progressive, a small perturbation is increased to change the solar panel power. Conversely, negative delta power specifies that the desired point is distant from operating point and so the voltage agitation is reduced to influence the MPPT. Hence, entire PV curvature is patterned in this way by slight perturbations to catch the MPPT which upturns the algorithm feedback time.

\subsection{Battery Model}

Generally of the battery models are categorized into two kinds which are electrochemical model and Equivalent Circuit Model (ECM). Electrochemical model thoroughly calculates battery's interior chemical repercussion that includes investigative complexity and delinquency estimation to attain accuracy of the parameter. Conversely, ECM is based at external dynamic forms which can sidestep the full deviation of internal electrochemical progressions [16]. In addition, The 1st order RC model cannot pronounce dynamic actions of batteries satisfactorily as well as third or higher order models are enormously sensitive for noises and measurement errors [17]. As a consequence, this paper comprises the second-order Thevenin ECM that is mentioned in Fig.3; $\mathrm{V}_{\mathrm{L}}$ is the terminal voltage, $\mathrm{V}_{\mathrm{OC}}$ is $\mathrm{OCV}$ and the relationship between this two parameter can be defined from (5).

$$
V_{L}=V_{O C}-I_{L} * R_{0}-\int \frac{I_{L}-I_{1}}{C_{1}} d t-\int \frac{I_{L}-I_{2}}{C_{2}} d t
$$

Where, $I_{1}=V_{1} / R_{1}$ and $I_{2}=V_{2} / R_{2}$

\subsection{State of Charge Estimation}

The SOC assessment accuracy is remarkable on behalf of Lead-Acid battery to confirm its protection maneuver and keep away the over-charging or deep-discharging issues. Nonetheless, SOC inference raises an objection for battery bank

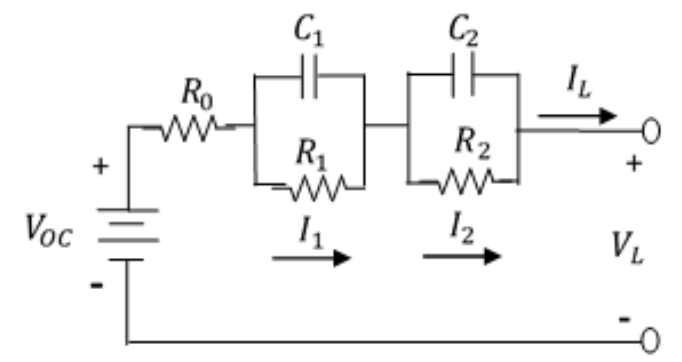

Fig. 3 - Thevenin Equivalent Circuit Model for battery

on account of the aforementioned nonlinear electrochemical outcomes [18]. Subsequently, SOC appraisal is contained via BPNN algorithm for this research. The structure of BPNN algorithmic formula is appeared in Fig. 4 [19][20]. The proposed model collects three input factors namely voltage, current and temperature from battery bank headed for estimating the present SOC conferring the equations from (6) to (12). Moreover, Root Mean Square Error (RMSE) is 
produced by adjusting the weights of the SOC model in an attempt to interpret the accurate outcomes. Totally, an individual hidden layer neuron input is reflected through (6)

$$
n e t i_{n}=\sum_{i=1}^{3} x_{i} w_{i n}+b_{n}
$$

Where, over-all input of an specific hidden neuron is neti $i_{n}$, the input neuron value is $x_{i}, w_{i n}$ is a weight that draws relation between input neuron $x_{i}$ to the individual hidden neuron $n, b_{n}$ is hidden neuron bias.

$$
\begin{gathered}
h_{n}=f\left(\text { net }_{n}\right)=\frac{1-\exp \left(-2 n e t i_{n}\right)}{1+\exp \left(-2 n e t i_{n}\right)} \\
\text { neto }=\sum_{i=1}^{n} h_{i} g_{i}+p
\end{gathered}
$$

Here, total input of output neuron o is neto, hidden layer neuron value is $h_{i}, g_{i}$ is a weigh value that partakes relation concerning hidden neuron $i$ with output neuron $o$, output neuron bias is $p$. Sigmoid function is the related activation role of output neuron. Calculation of output $y_{n}$ is drawn from (9)

$$
y_{n}=f(\text { neto })=\frac{1}{1+\exp (\text { neto })}
$$

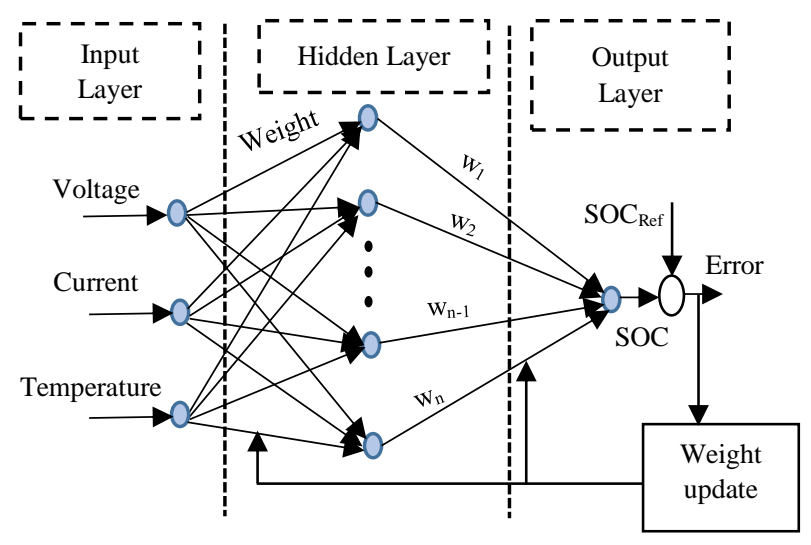

Fig. 4 - Structural design of BPNN algorithm

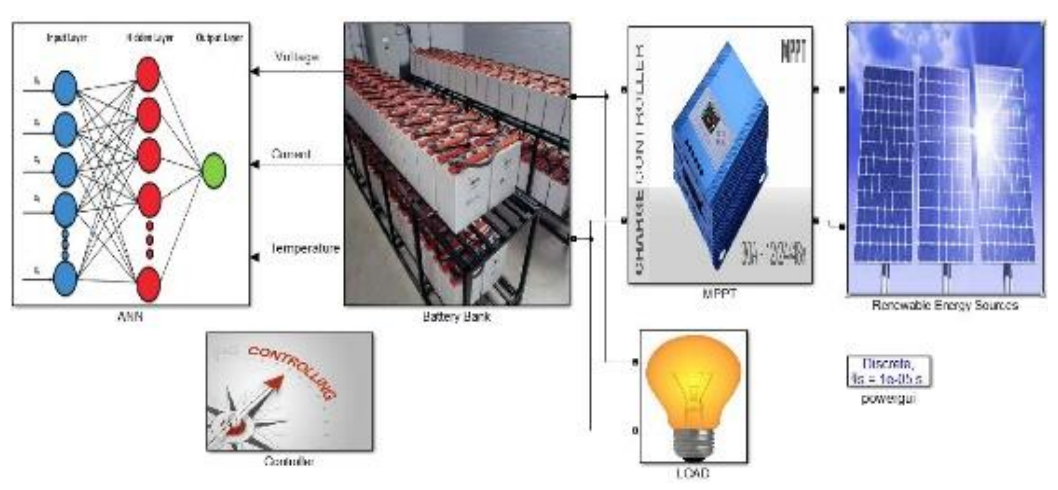

Fig. 5 - Simulink configuration of the proposed model 


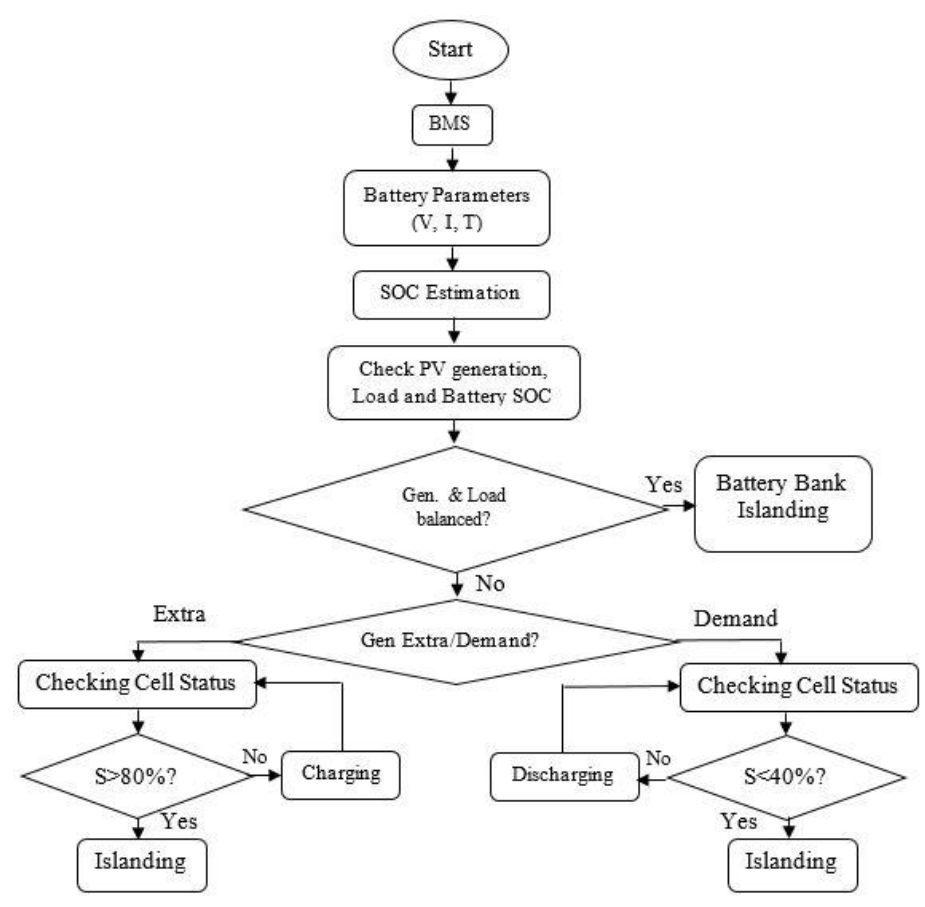

Fig. 6 - Flowchart of the entire system

a

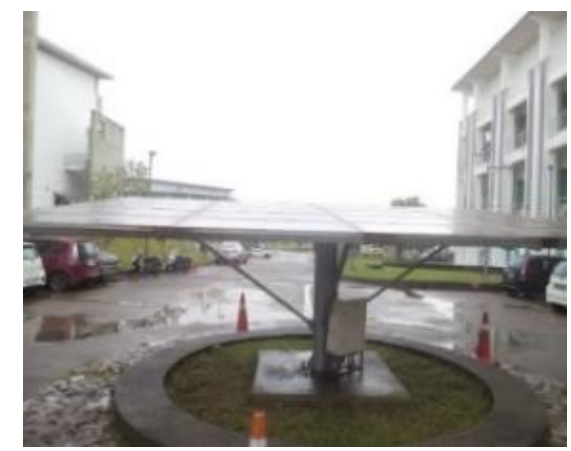

$\mathrm{b}$

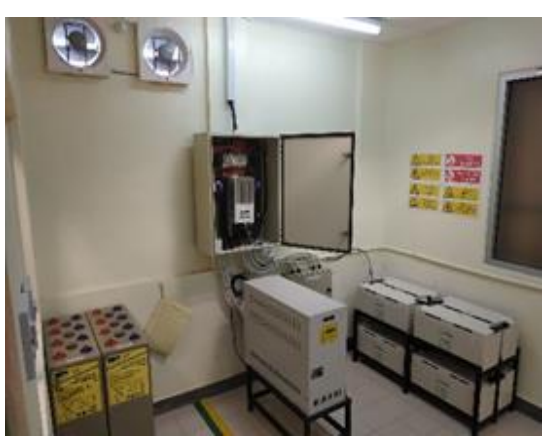

Fig. 7 - (a) Combined Solar Panel; (b) System Controlling Room

The error is calculated from (10). To obtain the desired output and reduce the error, the weights are updated repeatedly by gradient descent algorithm (11) to (12). The optimized weights are acquired when the error is minimized.

$$
\begin{gathered}
R M S E=\sqrt{\left(\sum_{i=1}^{n} e_{i}^{2}\right) / n} \\
e_{i}=f_{\text {Ref }}-f_{E S t} \\
\frac{\partial E r r o r}{\partial w_{i j}^{n}}=\frac{\partial E r r o r}{\partial f_{E s t}} \frac{\partial f_{E s t}}{\partial w_{i j}^{n}}
\end{gathered}
$$

\section{Simulation Result and Discussion}

To facilitate the convenience of expected BMS, the projected modeling is pretended in Matlab/Simulink atmosphere (Fig. 5). In case of any circumstances for solar irradiance and ambient temperature, PV boards are functioned at MPPT scheme to cause determined probable power successfully. Oppositely, battery SOC is estimated with the help of BPNN technique as well through receiving the battery parameters. Though battery SOC can be varied from $0 \%$ to $100 \%$ at 
charging/discharging mode, in case of removing the overcharging/deep discharging of the storage system, $40 \%$ to $80 \%$ SOC is considered as an operating charge status for battery bank. BMS compares the estimated SOC and MPPT supply voltage with the reference SOC and PV voltage continuously as well as takes decision about the battery bank charging, discharging or islanding mode. A complete flowchart of the deliberated stratagem is given away in Fig. 6.

In this project, 48V, 300Ah HOPPECKE solar.bloc Lead-Acid battery is installed with $3.5 \mathrm{~kW}$ NT175E1 PV $\left(\mathrm{V}_{\mathrm{OC}}=44 \mathrm{~V}, \mathrm{I}_{\mathrm{SC}}=5.4 \mathrm{~A}, \mathrm{Pm}=175 \mathrm{~W}\right)$ solar system (Fig. 7). Independently, 4 working days were studied (March-April, 2019) for a fixed load (2000Watt) from Renewable Energy Lab of Universiti Malaysia Sarawak that is mentioned in Fig. 8(a) to Fig. 8(d). Firstly in Fig. 8(a), 80\% SOC containing battery was tested in $1100 \mathrm{~W} / \mathrm{m}^{2}$ solar radiation and $33^{\circ} \mathrm{C}$ temperature to investigate the situation. Since sufficient power (nearly $2800 \mathrm{~W}$ ) was provided from PV supply to the load demand and battery was contented with the maximum SOC suitably, the storage system was resulted in the islanding mode on that day. In Fig 8(b), the second day of $1000 \mathrm{~W} / \mathrm{m}^{2} 31^{\mathrm{O}} \mathrm{C}, 70 \%$ SOC comprising battery was experimented that brought about the charging mode. Because the PV system was adequate (nearly $2500 \mathrm{~W}$ ) to deliver the load demand and charge the battery set satisfactorily. Furthermore, the project was carried out in $50 \% \mathrm{SOC}, 800 \mathrm{~W} / \mathrm{m}^{2} 27^{\circ} \mathrm{C}$ for $3 \mathrm{rd}$ day (Fig 8(c)) and on that day the battery bank was resulted in the discharging mode. Because, PV supply power (nearly $1700 \mathrm{~W}$ ) was insufficient on that day to cover the load demand owing to the cloudy condition. Lastly, the BMS is analyzed for $40 \%$ SOC battery status with $600 \mathrm{~W} / \mathrm{m}^{2} 23^{\circ} \mathrm{C}$ atmosphere. From Fig. 8(d), the situation of the 4th day can be described appropriately. Since, this is a standalone/off-grid system and in this day, the PV supply (nearly 1000W) cannot meet the load demand as well as the battery charge level is reached for the safest minimum states to support the capacity. Hence, BMS stopped the load file to prolong the battery life from Deep of Discharge. To improve the application facility of the research production, PV DC/DC voltage was converted into $240 \mathrm{~V}, 50 \mathrm{~Hz}$ AC supply as well that is displayed in Fig. 9.
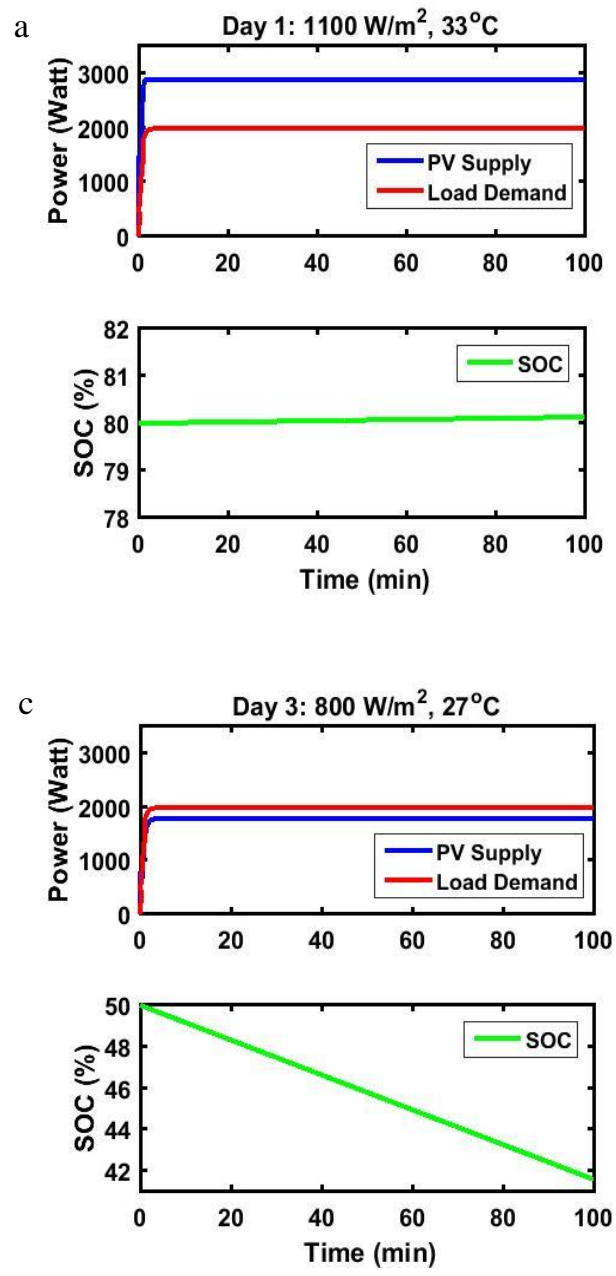
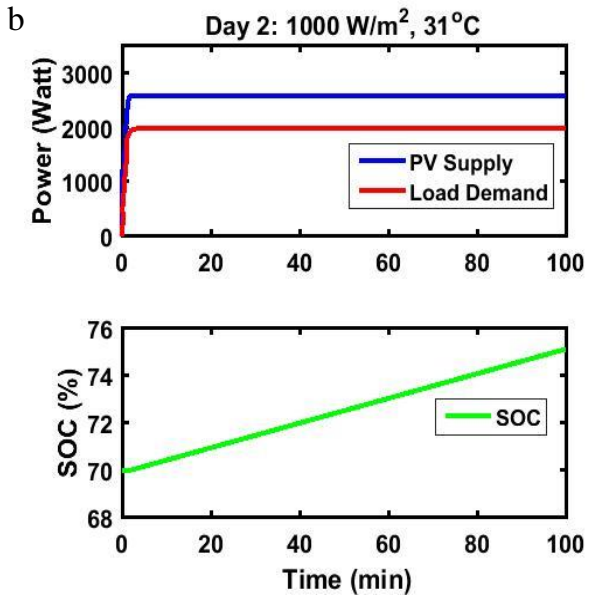

d
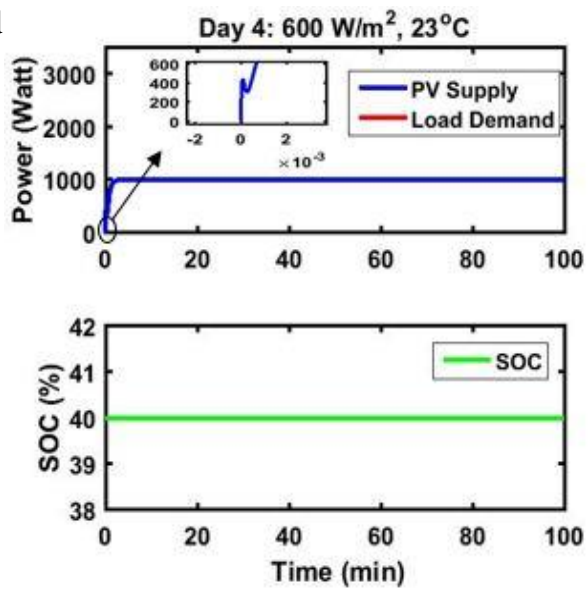

Fig. 8 - Simulation analysis for different days (a) Day 1: $1100 \mathrm{~W} / \mathrm{m}^{2}, 3^{\circ} \mathrm{C}$; (b) Day 2: 1000 $\mathrm{W} / \mathrm{m}^{2}, 3^{\circ} \mathrm{C}$; (c) Day 3: $800 \mathrm{~W} / \mathrm{m}^{2}, 2^{\circ} \mathrm{C}$; (d) Day 4: $600 \mathrm{~W} / \mathrm{m}^{2}, 2^{\circ} \mathrm{C}$ 

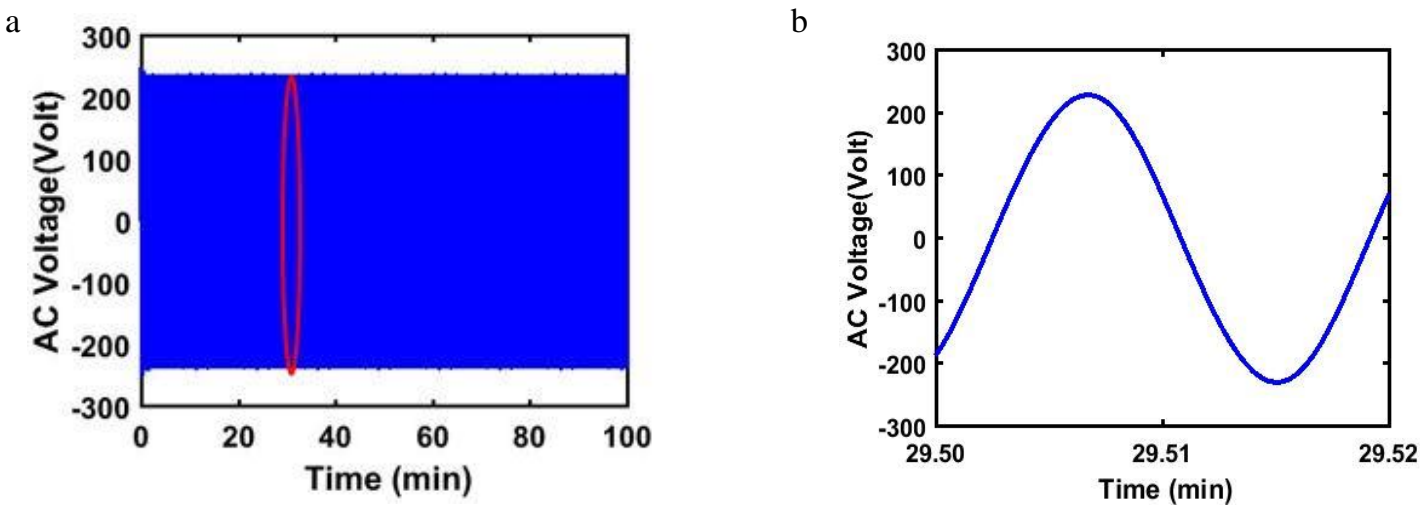

Fig. 9 - AC Voltage (a) Density; (b) Pure Sine wave for a particular moment
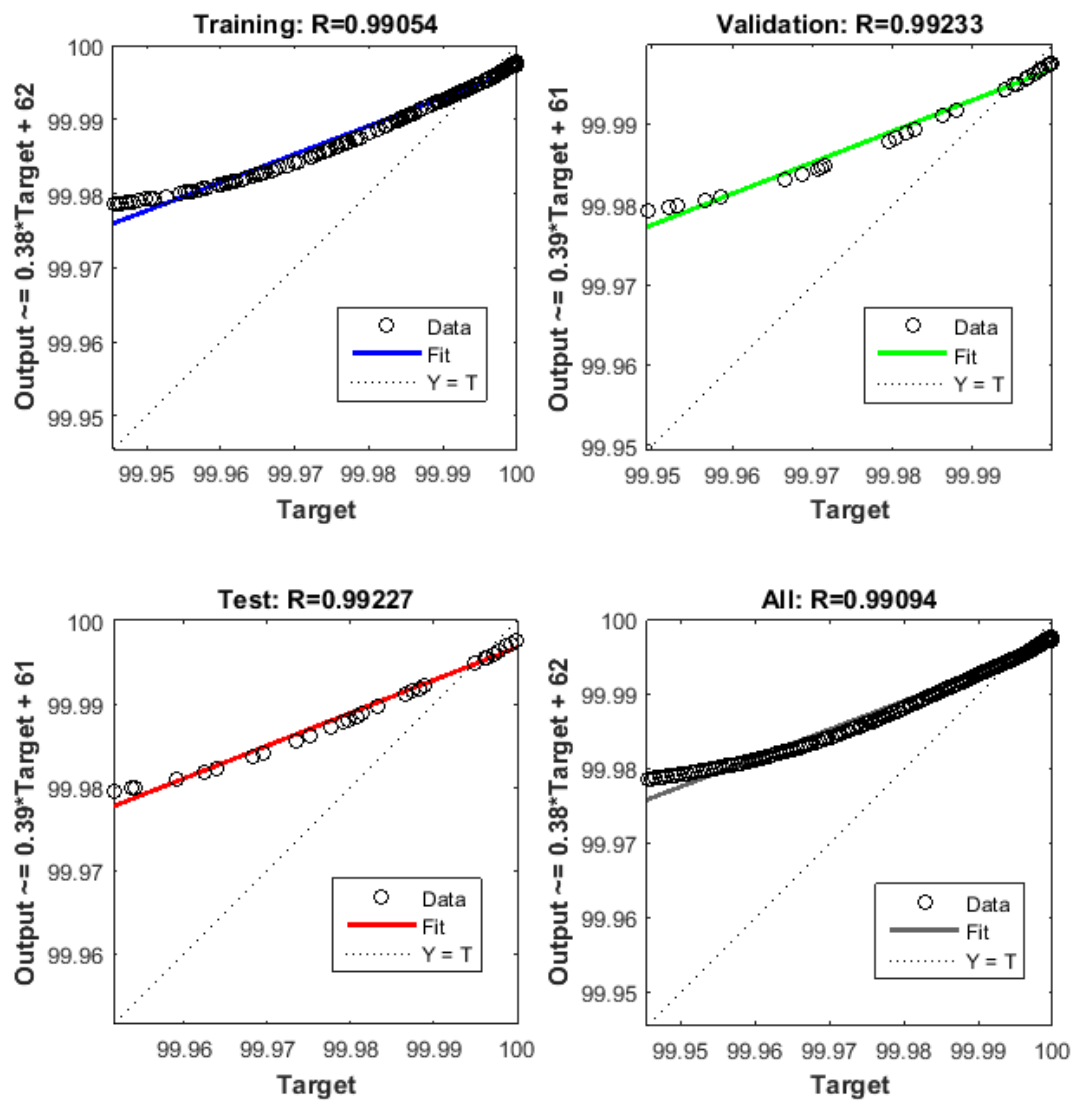

Fig. 10 - Training, Testing and Validation result in Matlab software 


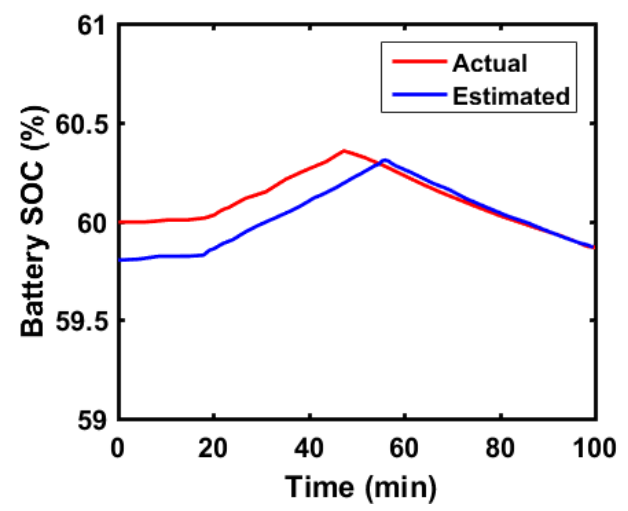

Fig. 11 - SOC comparison between Actual and Estimation data

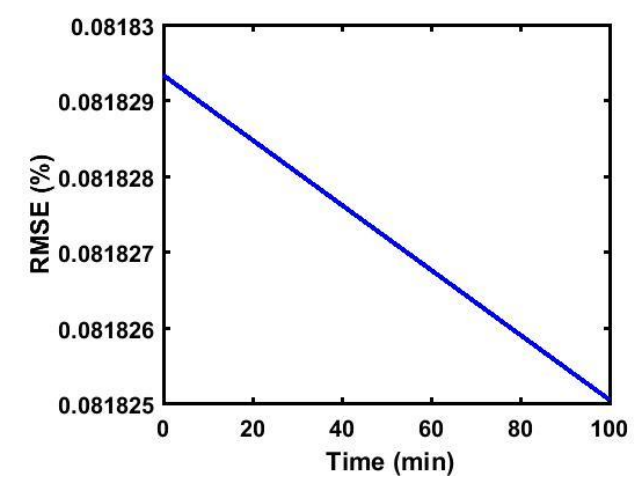

Fig. 12 - RMSE of the system

Table 1 - SOC Estimation Comparison

\begin{tabular}{ccccc}
\hline Ref. & Year & Battery & $\begin{array}{c}\text { SOC } \\
\text { Algorithm }\end{array}$ & $\begin{array}{c}\text { Error } \\
(\%)\end{array}$ \\
\hline$[21]$ & 2016 & LIB & PI Observer & 3 \\
{$[22]$} & 2017 & LIB & EKF & 6.5 \\
{$[23]$} & 2017 & LIB & EKF & 3 \\
{$[24]$} & 2018 & LIB & UKF & 1.5 \\
{$[25]$} & 2019 & LIB & EKF & 2 \\
$\begin{array}{c}\text { Projected } \\
\text { Model }\end{array}$ & 2019 & Lead & BPNN & 0.082 \\
\hline
\end{tabular}

Fig. 9(a) expresses the density of the system AC voltage and Fig. 9(b) indicates the creation of pure AC voltage (sine wave) in a certain time range (29.50 $\mathrm{min}-29.52 \mathrm{~min})$.

The intact system efficiency primarily depends on the truthful SOC estimation of battery bank. The collected battery data is trained in Matlab software. Among the 200 data, $70 \%$ (140), 15\% (30) and 15\% (30) data was executed randomly for training, testing and validation set respectively. The Training, Testing and Validation result is shown in Fig. 10. The regression is noticed as $99 \%$ which is satisfactory for the execution. SOC comparison between Actual and Estimation data is shown in Fig. 11 which is nearly same that supports the implementation of the novel research. Furthermore, though a few authors researched on SOC estimation accuracy in consort with Proportional Integral (PI) Observer, EKF, 
Unscented Kalman Filter (UKF) etc, BPNN algorithm yields the minimum error (0.082\%) in contrast with other reputed methods by means of weight regulation system. Fig. 12 indicates the RMSE of the assessed SOC, plus the confirmation of the proposed methodology can be permitted through Table 1 comparing to the previous projected methods.

\section{Conclusion}

Battery stowage approach is one of the most expensive but reliable technique in case of PV-storage standalone system. During the night time or cloudy day, the PV arrays cannot harvest energy and battery power is the only supplied energy that can support load at that moment. A framework consisting of BMS controller, single diode based PV model, P\&O MPPT technique, BPNN based SOC estimation is simulated in this work. Actual solar insolation and atmospheric thermo data collected from real world application is used in the simulation. The foremost objective of this work is to maintain a safe SOC window aimed at the prevention of overcharging/deep-discharging disorders for well-regulated BMS. Efficient simulation is pursued to implement Lead-Acid battery bank for the proposed structure to brand the unsurpassed use of energy storage system incorporated with PV-solar system. The control strategy regulates the SOC and makes decisions to touch the desired operative goals by means of lengthening the battery life-time. In comparison with the estimated SOC (RMSE 0.082\%) and control approach on real world batteries, PV-BMS justification investigations directed on this platform are safer away from normal sort of process, specifically at early periods of enlargement practice. Additionally number of battery elements and its enactments will also be explored based on the proposed background in the future exploration.

\section{Acknowledgement}

Financial support of this research is conveyed by Research and Innovation Management Center (RIMC) UNIMAS via Fundamental Research Grant Scheme FRGS/1/2017/TK10/UNIMAS/03/1, Ministry of Higher Education, Malaysia.

\section{References}

[1] Esan, A. B., Agbetuyi, A. F., Oghorada, O., Ogbeide, K., Awelewa, A. A., \& Afolabi, A. E. (2019). Reliability assessments of an islanded hybrid PV-diesel-battery system for a typical rural community in Nigeria. Heliyon, 5, $1-13$

[2] Ghenai, C., \& Bettayeb, M. (2019). Modelling and performance analysis of a stand-alone hybrid solar PV/Fuel Cell/Diesel Generator power system for university building. Energy, 171, 180-189

[3] Lasheen, M., \& Abdel-Salam, M. (2018). Maximum power point tracking using Hill Climbing and ANFIS techniques for PV applications: A review and a novel hybrid approach. Energy Conversion and Management, 171, 1002-1019

[4] Ishaque, K., Salam, Z., \& Lauss, G. (2014). The performance of perturb and observe and incremental conductance maximum power point tracking method under dynamic weather conditions. Applied Energy, 119, 228-236

[5] Kamran, M., Mudassar, M., Fazal, M. R., Asghar, M. U., Bilal, M., \& Asghar, R. (2018). Implementation of improved Perturb \& Observe MPPT technique with confined search space for standalone photovoltaic system. Journal of King Saud University - Engineering Sciences, 4, 275-284

[6] Yang, Y., Bremner, S., Menictas, C., \& Kay, M. (2018). Battery energy storage system size determination in renewable energy systems: A review. Renewable and Sustainable Energy Reviews, 91, 109-125

[7] Ci, S., Lin, N., \& Wu, D. (2016). Reconfigurable Battery Techniques and Systems: A Survey. IEEE Access, 4, 1175-1189

[8] Lee, S., Cherry, J., Safoutin, M., \& McDonald, J. (2017). Modeling and Validation of 12V Lead-Acid Battery for Stop-Start Technology. SAE International, 28, 1-11

[9] Natsheh, E. M., \& Albarbar, A. (2012). Solar power plant performance evaluation: simulation and experimental validation. Journal of Physics: Conference Series, 364, 1-14

[10] Alramlawi, M., Gabash, A., Mohagheghi, E., \& Li, P. (2018). Optimal operation of hybrid PV-battery system considering grid scheduled blackouts and battery lifetime. Solar Energy, 161, 125-137

[11] Yu, Y., Narayan, N., Vega-Garita, V., Popovic-Gerber, J., Qin, Z., Wagemaker, M., \& Zeman, M. (2018). Constructing Accurate Equivalent Electrical Circuit Models of Lithium Iron Phosphate and Lead-Acid Battery Cells for Solar Home System Applications. Energies, 11, 1-20

[12] Devarakonda, L., \& Hu, T. (2014). Algebraic method for parameter identification of circuit models for batteries under non-zero initial condition. Journal of Power Sources, 268, 928-940

[13] Bendib, B., Belmili, H., \& Krim, F. (2015). A survey of the most used MPPT methods: Conventional and Yonis et al., Int. J. of Integrated Engineering Vol. 12 No. 6 (2020) p. 148-157 157 advanced algorithms applied for photovoltaic systems. Renewable and Sustainable Energy Reviews, 45, 637-648 
[14] Castro, R. (2018). Data-driven PV modules modelling: Comparison between equivalent electric circuit and artificial intelligence based models. Sustainable Energy Technologies and Assessments, 30, 230-238

[15] Qays, O., \& Yasmin, F. (2020). Renewable energy production based on solar power and magnetic field prototype in Bangladesh. International Journal of Applied Power Engineering, 8, 29-35

[16] Abdel-Salam, M., El-Mohandes, M. T., \& Goda, M. (2018). An improved perturb-and-observe based MPPT method for PV systems under varying irradiation levels. Solar Energy, 171, 547-561

[17] Cui, W. H., Wang, J. S., \& Chen, Y. Y. (2018). Equivalent circuit model of lead-acid battery in energy storage power station and its state-of-charge estimation based on extended kalman filtering method. Engineering Letters, 26, 504-517

[18] Orchard, M. E., Roberto, C., Burgos, C., \& Doris, S. (2015). Fuzzy modelling for the state-of-charge estimation of lead-acid batteries, 274, 355-366

[19] Xiong, R., Cao, J., Yu, Q., He, H., \& Sun, F. (2017). Critical Review on the Battery State of Charge Estimation Methods for Electric Vehicles. IEEE Access, 6, 1832-1843

[20] Qays, O., Buswig, Y., \& Anyi, M. (2019). Active Cell Balancing Control Method for Series-Connected LithiumIon Battery. International Journal of Innovative Technology and Exploring Engineering, 8, 2424-2430

[21] Hannan, M. A., Lipu, M. S. H., Hussain, A., Saad, M. H., \& Ayob, A. (2018). Neural network approach for estimating state of charge of lithium-ion battery using backtracking search algorithm. IEEE Access, 6, 1006910079

[22] Zhang, C., Jiang, J., Zhang, L., Liu, S., Wang, L., \& Loh, P. C. (2016). A generalized SOC-OCV model for lithium ion batteries and the SOC estimation for LNMCO battery. Energies, 9, 1-16

[23] Campestrini, C., Kosch, S., \& Jossen, A. (2017). Influence of change in open circuit voltage on the state of charge estimation with an extended Kalman filter. Journal of Energy Storage, 12, 149-156

[24] Baccouche, I., Jemmali, S., Manai, B., Omar, N., Amara, N., Baccouche, I., \& Najoua, E. B. A. (2017). Improved OCV Model of a Li-Ion NMC Battery for Online SOC Estimation Using the Extended Kalman Filter. Energies, 10 , $1-22$

[25] Wang, W., Wang, X., Xiang, C., Wei, C., \& Zhao, Y. (2018). Unscented kalman filter-based battery SOC estimation and peak power prediction method for power distribution of hybrid electric vehicles. IEEE Access, 6, 35957-35965

[26] Ren, H., Zhao, Y., Chen, S., \& Wang, T. (2019). Design and implementation of a battery management system with active charge balance based on the SOC and SOH online estimation. Energy, 166, 908-917 